\title{
In Vivo Observation of Structural Changes in Neocortical Catecholaminergic Projections in Response to Drugs of Abuse
}

Mai M. Morimoto, ${ }^{1,2,{ }^{\ddagger}}$ Shinji Tanaka, ${ }^{1}$ Shunsuke Mizutani, ${ }^{1}$ Shinji Urata, ${ }^{1}$ Kazuto Kobayashi, ${ }^{3}$ and (1) Shigeo Okabe ${ }^{1}$

DOI:http://dx.doi.org/10.1523/ENEURO.0071-17.2018

${ }^{1}$ Department of Cellular Neurobiology Graduate School of Medicine, University of Tokyo, Bunkyo-ku, Tokyo, 113-0033 Japan,

${ }^{2}$ Department of Experimental Psychology, University College London, 26 Bedford Way, WC1H OAP, London, UK, and ${ }^{3}$ Department of Molecular Genetics, Institute of Biomedical Sciences, Fukushima Medical University School of Medicine, 960-1295 Japan

\section{Visual Abstract}

\section{Under normal condition}

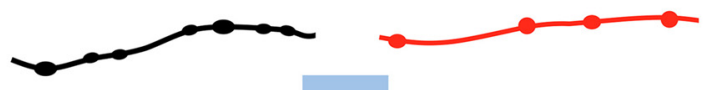

\section{$24 h$}

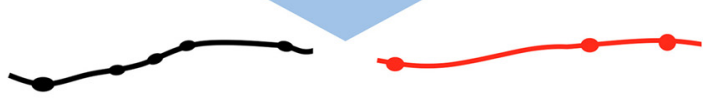

Bouton Turnover

Catecholaminergic axon > Pyramidal neuron axon

Spatial rearrangement of boutons could be a mechanism

for regulation of local catecholamine transmission

In response to drugs of abuse

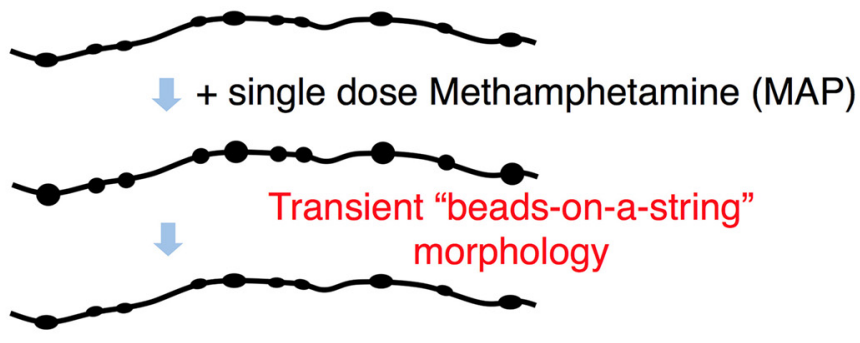

Bouton volume change could be related to presynaptic functional change triggered by MAP 


\section{Significance Statement}

This work demonstrates a novel approach for longitudinal two-photon in vivo monitoring of catecholaminergic projections in the neocortex using a tyrosine hydroxylase promoter-green fluorescent protein (GFP) transgenic mouse. Using this method, we revealed the highly dynamic nature of the catecholaminergic projections over $24 \mathrm{~h}$ period, and a transient morphologic change of these axons in response to a drug of abuse, methamphetamine (MAP). To our knowledge, this is the first observation of such MAP-induced morphologic change of catecholamine axons in vivo. In the future, this new method can be extended to observe structural changes associated with cortical development, learning, and mental disorders, in which catecholamine projections to the cortex are known to play a key role.

Catecholaminergic (dopamine and norepinephrine) projections to the cortex play an important role in cognitive functions and dysfunctions including learning, addiction, and mental disorders. While dynamics of glutamatergic synapses have been well studied in such contexts, little is known regarding catecholaminergic projections, owing to lack of robust methods. Here we report a system to monitor catecholaminergic projections in vivo over the timeframes that such events occur. Green fluorescent protein (GFP) expression driven by tyrosine hydroxylase promoter in a transgenic mouse line enabled us to perform two-photon imaging of cortical catecholaminergic projections through a cranial window. Repetitive imaging of the same axons over $24 \mathrm{~h}$ revealed the highly dynamic nature of catecholaminergic boutons. Surprisingly, administration of single high dose methamphetamine (MAP) induced a transient increase in bouton volumes. This new method opens avenues for longitudinal in vivo evaluation of structural changes at single release sites of catecholamines in association with physiology and pathology of cortical functions.

Key words: axon; catecholamine; in vivo imaging; methamphetamine; neocortex; transgenic mouse

\section{Introduction}

Neuromodulators, such as monoamines and cholines, exert their functions through axonal projection systems that distribute widely throughout the mammalian brain. Neuromodulators control global brain states including arousal, motivation, mood, and stress. Among them, functional significance of the catecholaminergic system, consisting of dopaminergic and norepinephrinergic neurons, has been well documented (Robbins and Arnsten, 2009). For example, the disruption of their axonal terminals or receptor blockage in the prefrontal cortex (PFC) of monkeys and rats have resulted in impairment of their

Received March 2, 2017; accepted January 4, 2018; First published January 22, 2018.

The authors declare no competing financial interests.

Author contribution: M.M.M., K.K., and S.O. designed research; M.M.M., S.T., S.M., and S.U. performed research; M.M.M. analyzed data; M.M.M. and S.O. wrote the paper.

This work was supported by Grants-in-Aid for Scientific Research 17H01387, 26250014, and 25117006 (to S.O.) and the Core Research for Evolutional Science and Technology from the Japan Science and Technology Agency Grant JPMJCR14W2 (to S.O.), Uehara Memorial Foundation (S.O.), and University of Tokyo Center for Integrative Science of Human Behavior.

${ }^{\ddagger}$ Current address: Department of Experimental Psychology, University College London, 26 Bedford Way, WC1H OAP, London, UK.

Acknowledgements: We thank Dr. Satoru Kondo for assistance with twophoton microscopy, Dr. Susumu Jitsuki for conducting the microdialysis experiments, and all members of the Okabe lab for discussions and comments.

Correspondence should be addressed to Shigeo Okabe at the above address, E-mail: okabe@m.u-tokyo.ac.jp.

DOI:http://dx.doi.org/10.1523/ENEURO.0071-17.2018

Copyright (C) 2018 Morimoto et al.

This is an open-access article distributed under the terms of the Creative Commons Attribution 4.0 International license, which permits unrestricted use, distribution and reproduction in any medium provided that the original work is properly attributed. spatial working memory (Bubser and Schmidt, 1990; Sawaguchi and Goldman-Rakic, 1991; Li and Mei, 1994; Zahrt et al., 1997). Moreover, when catecholamine receptors were stimulated with agonists, PFC neurons' firing became more finely tuned to relevant stimuli, suggesting a role for catecholamines in the "gating" of signals (Vijayraghavan et al., 2007). Dopamine has classically been known to provide the reward signal in reinforcement learning in the form of "reward prediction error" (Schultz et al., 1997). More recently, synaptic mechanisms have begun to be elucidated, suggesting that temporally precise dopamine signal is necessary for learning (Yagishita et al., 2014).

Catecholamines possess an inverted U-shaped doseresponse curve, having an optimal range of concentration for different tasks (Seamans and Yang, 2004). Drugs of abuse, such as methamphetamine (MAP), cocaine, and 3,4-methylenedioxy-MAP (MDMA), act on catecholaminergic systems and raise their extracellular levels to suboptimal high ranges, leading to detrimental effects on cognitive and behavioral states of the subject. Furthermore, antagonists of dopamine and norepinephrine receptors and transporters have been effective in the treatment for major depression, schizophrenia, and attention deficit hyperactive disorder (ADHD), which strongly suggest the alteration of the catecholamine system in these mental disorders (Gamo and Arnsten, 2011). There have been reports of reduced catecholaminergic innervation in postmortem tissues of human patients diagnosed with schizophrenia (Akil et al., 1999) and in a mouse model of schizophrenia (Sekiguchi et al., 2011).

All of these cognitive functions and dysfunctions progress at the time scale of days to months. Longitudinal 
monitoring of the microstructures of catecholamine neurons could provide insights into synaptic-level mechanisms underlying the progression of these events. While the longitudinal structural imaging of axons and dendrites of pyramidal neurons and some inhibitory neurons have become feasible with Thy-1-green fluorescent protein (GFP) transgenic mice and in utero electroporation approach (Feng et al., 2000; Lee et al., 2005; Isshiki et al., 2014), imaging of other cell types in the mammalian neocortex has been limited by lack of appropriate genetic methods. More recently, the labeling of different cell types has become possible with the use of Cre-lines and virus mediated methods (Huang et al., 2014; Mastwal et al., 2014). However, with these methods, achieving a homogeneously high and long-lasting stability of expression necessary for longitudinal in vivo imaging is generally still a challenge. Also, with some Cre-lines such as tyrosine hydroxylase promoter (Th)-Cre, cell type specificity is not guaranteed, often requiring an additional step of confirming the cell type through retrospective immunohistochemistry (Lammel et al., 2015; Stuber et al., 2015).

Here, we developed a method for longitudinal structural imaging of catecholaminergic axons in vivo using the Th-GFP transgenic mouse. These transgenic mice show high expression and reliable labeling for typical catecholaminergic cell groups [ex. ventral tegmental area $(\mathrm{VTA})=85.2 \%$, substantia nigra pars compacta $(\mathrm{SNc})=$ 94.1\%; Matsushita et al., 2002]. We examined the morphology of catecholaminergic axons and their structural changes over $24 \mathrm{~h}$ through a cranial window with twophoton microscopy. Quantitation of bouton turnover revealed a higher dynamic fraction for catecholamine neurons compared to Layer II/III pyramidal neurons. During an acute imaging session, a single high dose of MAP induced a transient "beads-on-a-string" morphology of catecholaminergic axons. The present study reveals the details of the catecholaminergic axon dynamics in vivo in timescales of minutes to a day in the adult mouse neocortex.

\section{Materials and Methods}

\section{Animals}

For in vivo imaging of catecholaminergic axons, transgenic mice expressing GFP under the tyrosine hydroxylase promoter (Th-GFP mice) were used (21-31 line; Matsushita et al., 2002). The transgenic line was maintained by crossing to wild type C57BL/ $6 \mathrm{~J}$ inbred mice and heterozygotes aged two to four months were used for the experiments. This Th-GFP line labels TH positive neurons in the olfactory bulb, hypothalamus, midbrain and hindbrain regions. Since TH positive neurons in the olfactory bulb and hypothalamus are local neurons and do not project to the cortex (Nagayama et al., 2014; Zhang and van den Pol, 2015), the axons in this study originated mainly from the midbrain (VTA, SNr) and hindbrain (locus coeruleus; LC) regions, which harbor dopamine and norepinephrine neurons projecting to the cortex.

For in vivo imaging of pyramidal neuron axons, transgenic mice expressing yellow fluorescent protein (YFP) under the Thy-1 promoter (Thy-1-GFP mice, H-line) of similar ages were used (Feng et al., 2000). Both male and female animals were used. All animal procedures were performed in accordance with the University of Tokyo animal care committee's regulations.

\section{Surgery}

Mice were deeply anesthetized intraperitoneally with ketamine $(100 \mathrm{mg} / \mathrm{kg})$ and xylazine $(10 \mathrm{mg} / \mathrm{kg})$ diluted in saline. After disappearance of the foot pinch response, the hair of the scalp was shaved, and the scalp over the imaging area was removed. Periosteum tissue was removed with a surgical blade and the frontal or somatosensory area $(+2.7 \mathrm{~mm}$ from bregma and $0.5 \mathrm{~mm}$ lateral from midline, $-1.5 \mathrm{~mm}$ from bregma and $2.0 \mathrm{~mm}$ lateral from midline, respectively) was marked according to stereotactic coordinates. A small metal tube was glued on the skull with dental cement and mice were fixed to the immobilized stage (Narishige) with a heating pad to maintain its body temperature. The skull overlying the frontal cortex (AFC) or somatosensory cortex (SSC) was drilled with a high-speed drill (KM11, Minimo) with a ring type drill bit and carefully removed $(\varnothing 1.8 \mathrm{~mm})$. The dura was covered with a round cover glass (No. $1, \varnothing 3 \mathrm{~mm}$ ) and sealed in place with dental cement. After the surgery, in vivo time lapse imaging was performed with a two-photon microscope for 3-4 $\mathrm{h}$ within the same day, or $1-2 \mathrm{~h}$ in consecutive 2 days.

\section{In vivo two-photon imaging}

A scanning microscope (FV-300, Olympus) equipped with a mode-locked Ti: Sapphire laser (MaiTai HP, Spectra Physics) was used for imaging with a water immersion objective lens (1.05 NA, 25×, Olympus). The wavelength was $920 \mathrm{~nm}$, and the average power of the laser after the objective lens was between 30 and $40 \mathrm{~mW}$. The imaging area was $234 \times 234 \mu \mathrm{m}$ (low magnification) or $78 \times 78$ $\mu \mathrm{m}$ (high magnification), with an imaging depth $100 \mu \mathrm{m}$ from the surface of the neocortex (Layer I-II), and the step size of the z-stack set to $1.0 \mu \mathrm{m}$. The image sizes of single horizontal images were set to $512 \times 512$. For repetitive imaging between days, low magnification images and images of the surface vasculature pattern were taken with a CCD camera (GZ-MG70, Victor), which served as the reference maps for the acquisition of higher magnification images from the same cortical area. The mice were kept on the heating pad until they recovered from the anesthesia and were returned to their home cage.

\section{Drug administration}

MAP hydrochloride (Philopon, Dainippon Sumitomo Pharma; catalog number 871151) was diluted with saline at a concentration of $1 \mathrm{mg} / \mathrm{ml}$ for $10 \mathrm{mg} / \mathrm{kg}$ injection and $0.25 \mathrm{mg} / \mathrm{ml}$ for $2.5 \mathrm{mg} / \mathrm{kg}$ injection. Mice were subcutaneously injected with a single dose of 2.5 or $10 \mathrm{mg} / \mathrm{kg}$ MAP during the imaging session.

\section{In utero electroporation}

For visualization of cortical excitatory axonal processes in vivo, Layer II/III neural progenitor cells were transfected via in utero electroporation. E14.5-E15.5 pregnant mice were deeply anesthetized with pentobarbital. The uterine 
horns were exposed and $\sim 1 \mu$ l of DNA solution (containing $1.5 \mu \mathrm{g} / \mu \mathrm{l}$ of $\beta$-actin::DsRed2 plasmid) was injected into the lateral ventricle of each embryo via a glass capillary. Subsequently, the head of each embryo was placed between tweezer electrodes (CUY650P5, NEPA GENE), and four-square pulses (duration: $50 \mathrm{~ms}$, frequency: $1 \mathrm{~Hz}$, 29 V) were applied for electroporation (CUY21EDIT, NEPA GENE).

\section{In vivo microdialysis}

C57BL/6 J mice were anesthetized and stereotaxically implanted with stainless-steel guide cannula (outer diameter, $0.51 \mathrm{~mm}$; AG-4, Eicom Co) in the frontal cortex $(+2.7$ $\mathrm{mm}$ from bregma and $0.5 \mathrm{~mm}$ lateral from midline). After cannula implantation, a stylet was inserted into the guide until the microdialysis experiment, and was left to stabilize for more than a week.

Two hours before microdialysis experiment, the stylet was replaced with a dialysis probe with a 1.0-mm-long semipermeable membrane (outer diameter, $0.31 \mathrm{~mm}, \mathrm{Al}-$ 4-1, Eicom Co). A two-channel fluid swivel device (SSU20 , Eicom Co) was connected to the inlet and outlet of the probe and artificial CSF (147 mM NaCl, $4 \mathrm{mM} \mathrm{KCl}, 1.2 \mathrm{mM}$ $\mathrm{CaCl}_{2}$, and $0.9 \mathrm{mM} \mathrm{MgCl}_{2}$ ) was infused through the probe at a rate of $1.0 \mu \mathrm{l} / \mathrm{min}$ using a microdialysis pump (CMA 102, Carnegie Medicin). Each mouse was maintained individually in its cage and the dialysis was performed under ketamine $(100 \mathrm{mg} / \mathrm{kg})$ and xylazine $(10 \mathrm{mg} / \mathrm{kg})$ mixture anesthesia. Following equilibrium period ( $>2 \mathrm{~h}), 10$ samples were collected every 20 min in vials containing an equal volume $(20 \mu \mathrm{l})$ of acetic acid solution $(40 \mathrm{mM})$ with EDTA $(200 \mu \mathrm{M})$. The first four samples were baseline samples. Immediately after collection of the last baseline sample (after $80 \mathrm{~min})$, a single dose of MAP $(10 \mathrm{mg} / \mathrm{kg})$ was injected subcutaneously. Samples were stored at $-70^{\circ} \mathrm{C}$ until the HPLC assay.

Dopamine concentration in the dialysate was quantified by HPLC with a pump system (EP-300; Eicom Co). Each sample was injected into a separation column (Eicompak CAX, Eicom Co) with a mobile phase consisting of $0.1 \mathrm{M}$ ammonium acetate buffer at pH 6.0, 0.13 mM EDTA, 50 $\mathrm{mM}$ sodium sulfate, and $30 \%$ methanol. Samples were then separated out with a separation column maintained at $35^{\circ} \mathrm{C}$ and detected with an electrochemical detector (ECD-300, Eicom Co). The electrode potential was set to $400 \mathrm{mV}$ against an $\mathrm{Ag} / \mathrm{AgCl}$ reference electrode. The changes in electric current (nA) were recorded using an integrated data processor (Power Chrom EPC-500, Eicom Co). The dopamine concentration in the dialysate was calculated by reference to the peak area of the standard solution.

\section{Image and data analysis}

All image analyses were done using National Institutes of Health ImageJ and Fiji software (http://rsb.info.nih.gov/ ij) and custom-written MATLAB scripts (Mathworks).

For the $24 \mathrm{~h}$ repetitive imaging data, the same axonal segments $(30-80 \mu \mathrm{m})$ were identified from the image stacks from their three-dimensional location and the gross morphology of the axon, which did not change greatly over the course of a day. For quantification of bouton turnover, z-stack images containing only the axon segment of interest were sum intensity projected to include the whole arbor. This prevented any superimposing structures to be included in the projected image. We reconstructed the $x z$ plane of these stacks to check the presence of potential artifacts due to movements. Such artifacts would appear as discontinuities in the $X Z$ plane. We discarded datasets with such artifacts. Next, background intensity was subtracted from the whole image and the axon of interest was traced manually with a line selection tool in ImageJ. The intensity along the selected line was measured. Boutons that exhibited a peak intensity $>1.5$ times the average axon shaft intensity on day 0 were selected for analysis. If this bouton maintained its peak intensity $>1.5$ times than the axon shaft (baseline), then this bouton was scored as stable. If it fell below 1.2 times the baseline, it was scored as a loss. New peaks of intensity $>1.5$ times than baseline on day 1 were scored as gain only when it had an intensity below 1.2 times the baseline on day 0 . Turnover rates (TORs), the fraction of gained and lost boutons, were calculated as TOR $\left(t_{1}, t_{2}\right)=$ $\left(\mathrm{N}_{\text {gained }}+\mathrm{N}_{\text {lost }}\right) /\left(\mathrm{N}\left(\mathrm{t}_{1}\right)+\left(\mathrm{N}\left(\mathrm{t}_{2}\right)\right)\right.$, and survival fraction (SF) was calculated from [1-SF $\left.\left(t_{2}-t_{1}\right)\right] \approx$ TOR $\left(t_{1}, t_{2}\right)$ (Holtmaat et al., 2005). Statistical significance was evaluated using a two-tailed unpaired Student's $t$ test. Differences were considered to be significant for $p<0.05$.

Quantification of bouton volume changes by MAP treatment was done using a semiautomated method. First, 3D image of each time point was maximum intensity projected to 2D. This image was made for all time points and assembled into a stack, and registered using the "stackreg" function in ImageJ. Second, the "find maxima" function in ImageJ was used to obtain local maxima point coordinates for automatic bouton detection. Any points that did not overlap with boutons were excluded on visual inspection. Third, this list of local maxima point coordinates was imported into MATLAB, and a $3 \times 3$-pixel ROI was made around each point on each image in the stack. The ROI mean pixel intensity was calculated to assess the bouton volume change over time. Finally, all data were normalized to the time of MAP administration. Histograms were generated in MATLAB, in which data were pooled from "before," "after," and "recovery" time epochs (before = 20-40 min before MAP administration, after = 15-30 min after injection, and recovery $=60-100 \mathrm{~min}$ after injection).

\section{Results}

\section{Morphologic characteristics of catecholaminergic axons in the adult mouse neocortex imaged in vivo under normal conditions}

For visualizing the catecholaminergic neurons in vivo, we chose two-photon imaging using a cranial window preparation, which has been shown to be useful for structural imaging in the superficial layers of the cortex (Lee et al., 2005; Holtmaat et al., 2009; Xu et al., 2009). We imaged catecholaminergic axons innervating the Layer I-II (0-100 $\mu \mathrm{m}$ from pia) of the neocortex by two-photon microscope in vivo through a cranial window in adult Th-GFP transgenic mice. High expression levels of GFP and the relatively sparse innervation of catecholaminergic 
A
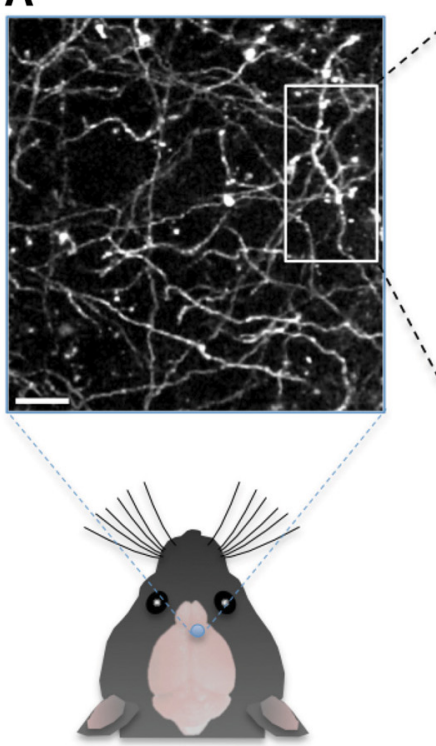

Th-GFP transgenic mouse
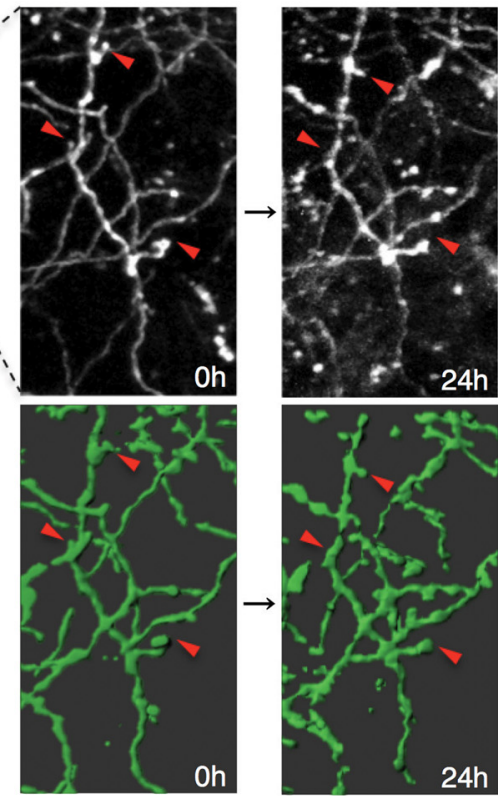

B
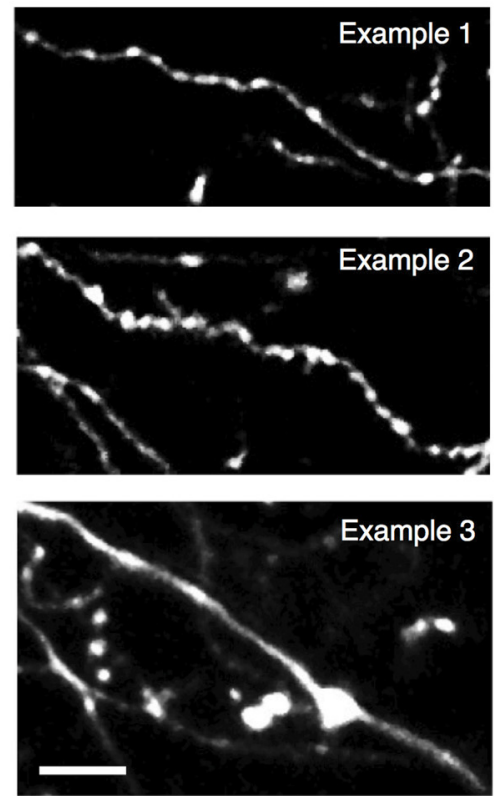

Figure 1. In vivo imaging of catecholaminergic axons labeled by Th-GFP transgenic line in the mouse neocortex. $\boldsymbol{A}$, In vivo two-photon image of catecholaminergic axons observed in Th-GFP transgenic mice. The same axons were repeatedly observed in following experiments. Grayscale images show Z-projections of image stack. Axons in green are 3D-rendered versions. Red arrowheads indicate change events. Scale bar: $15 \mu \mathrm{m}$. B, Representative morphology of the major three examples of catecholaminergic axons observed in Th-GFP transgenic mice. Most axons were thin and varicose, except for occasional large smooth fibers in deeper layers $(\sim 100 \mu \mathrm{m})$. Scale bar: $10 \mu \mathrm{m}$.

fibers in the neocortex enabled the clear identification of single axons and their detailed morphology (Fig. 1A).

We selected the prefrontal areas of the cortex (frontal association cortex, motor cortex 2, here designated as AFC; Van De Werd et al., 2010) for imaging based on a body of literature indicating catecholamine's functionally significant role in these areas (Arnsten, 1998; Robbins and Arnsten, 2009). We also imaged in the SSC, where the dynamics of glutamatergic boutons has been reported (De Paola et al., 2006; Holtmaat et al., 2009).

The catecholaminergic axon morphology in vivo was not homogeneous. Three notable morphologies were consistently observed (Fig. 1B): thin axonal shafts with relatively small boutons and intermediate bouton density (Fig. 1B, example 1), thicker axonal shafts with large boutons and high bouton density (Fig. 1B, example 2), with occasional side protrusions, and large diameter axonal shafts with very low bouton density (Fig. 1B, example 3). Axons similar to examples 1 and 2 were observed in superficial layers $(\sim 50 \mu \mathrm{m})$, whereas axons similar to example 3 was only seen in deeper layers $(\sim 100 \mu \mathrm{m})$. We observed that while axons similar to example 1 were found in all cortical areas studied (AFC and SSC), axons similar to example 2 were more frequently observed in SSC as compared to the AFC. Axons similar to example 3 were more prominent in the AFC than in the SSC.

These three morphologies closely resembled catecholamine immunoreactive fibers found in fixed brain slices of rats and human cerebral cortex (Berger et al., 1976; Lindvall et al., 1978; Smiley et al., 1992), suggesting a common axonal structure for catecholaminergic cells among the mammalian species.

\section{One-day interval two-photon time-lapse imaging} reveals dynamic structural changes of catecholaminergic axonal boutons and protrusions

To explore what structural changes occur in these catecholaminergic axons under unperturbed conditions over the timescale of a day, we obtained stack images of the same area of cortex (the AFC or SSC) each day and compared the morphologies of the axons. A variety of structural changes were observed that could be grouped into four categories (Fig. 2A,i-iv). When structural transitions were grouped into these categories (Fig. $2 B$ ), the loss and gain (turnover) of boutons was the most prominent among them, amounting to $\sim 77 \%$ of all observed changes (Fig. 2A). While turnover of boutons and small protrusions have also been previously observed in intracortical projections from pyramidal neurons (De Paola et al., 2006), the very occasional observation of gain or loss of a segment of axonal shaft Fig. $2 A$ (iv), $B(\mathrm{iv}))$ is a rather surprising event for a $24 \mathrm{~h}$ time interval.

To quantitate the dynamics of the boutons, we next measured the gain and loss of these boutons. To this end, we randomly selected well-isolated axonal segments from the stack images and compared the positions and numbers of boutons observed at each of the two time-points. Previous reports of turnover of excitatory cell boutons ( $\mathrm{De}$ Paola et al., 2006; Holtmaat et al., 2009) led us to expect relatively modest changes. In contrast, the dynamic fraction of catecholaminergic boutons was considerably higher (Fig. 3C). No significant difference was observed between the two areas studied (AFC and SSC; Fig. 3C, Table 1; $p=0.37^{\mathrm{a}}$ ). We controlled for potential confounding effects of the craniotomy on the turnover of boutons 
A

\section{Axonal morphology change types}

i) shaft (small bouton) $\rightleftarrows$ bouton

ii) shaft $\rightleftarrows$ protrusion

iii) bouton $\rightleftarrows$ bouton + protrusion

iv) shaft extension, retraction, winding

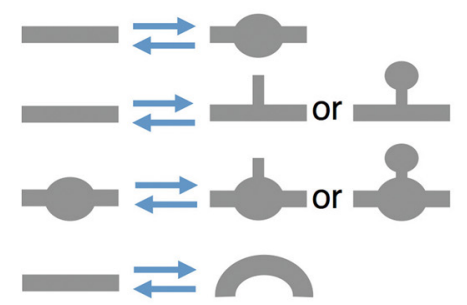

B
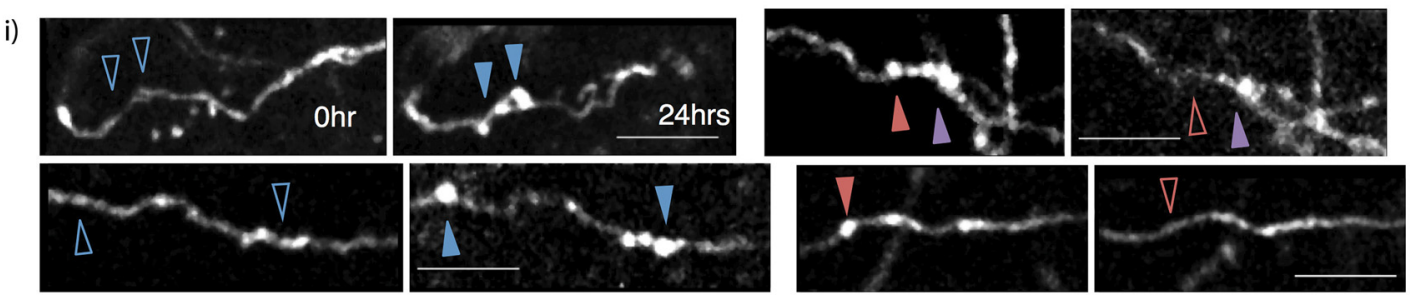

ii)
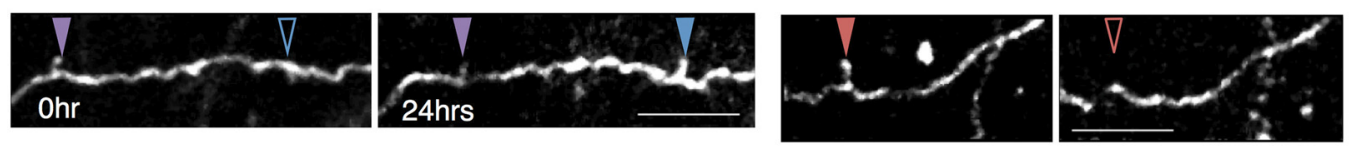

iii)
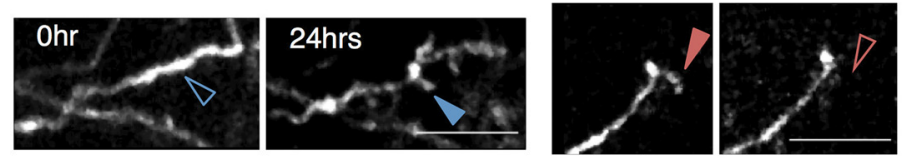

iv)
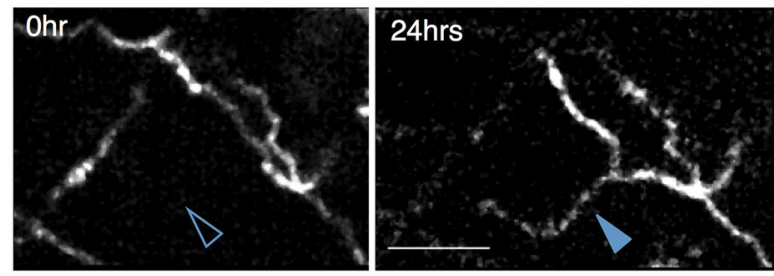

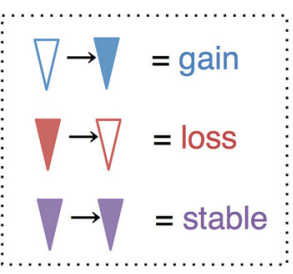
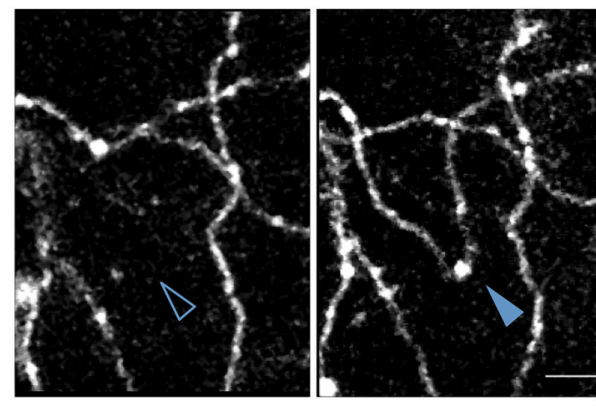

Figure 2. Morphologic changes of catecholaminergic axons over 24 h. A, Types of morphologic changes observed between the two time points $(0$ and $24 \mathrm{~h})$. $\boldsymbol{B}$, Examples of the grouped changes i-iv. Blue, red, and purple arrowheads indicate examples of gained, lost, and stable components, respectively.

by directly comparing the turnover of catecholaminergic axonal boutons with those of glutamatergic axons from pyramidal neurons. By labeling a subset of pyramidal neurons with a red fluorescent protein (DsRed2 driven by $\beta$-actin promotor) by in utero electroporation, both types of axons could be compared within the same transgenic mouse preparation (Fig. 3B). Quantitation of bouton turnover revealed a significantly larger dynamic fraction of boutons for catecholaminergic axons compared to pyramidal cell axons in the PFC (Fig. $3 C$, Table 1; TH AFC: $p$ $=1.9 \times 10^{-8 \mathrm{~b}}$, TH SSC: $p=9.8 \times 10^{-7 \mathrm{c}}$ ). The SF of Layer II/III pyramidal neuron boutons in our study over 24 h was $85.3 \%$. Importantly, this value was comparable with a previous report ( $\sim 90 \%$; De Paola et al., 2006). These data argued that craniotomy did not significantly impact the structural dynamics of catecholaminergic axons, and that the structural dynamics of presynaptic boutons is differentially regulated between glutamatergic and catecholaminergic axons within the same cortical area.

\section{High-dose MAP administration induces a transient} beads-on-a-string morphology of catecholaminergic axons

Drugs of abuse, such as MAP, cocaine or MDMA, act on monoaminergic systems and increase the extracellular level of monoamines in the neocortex (Darvesh et al., 
A
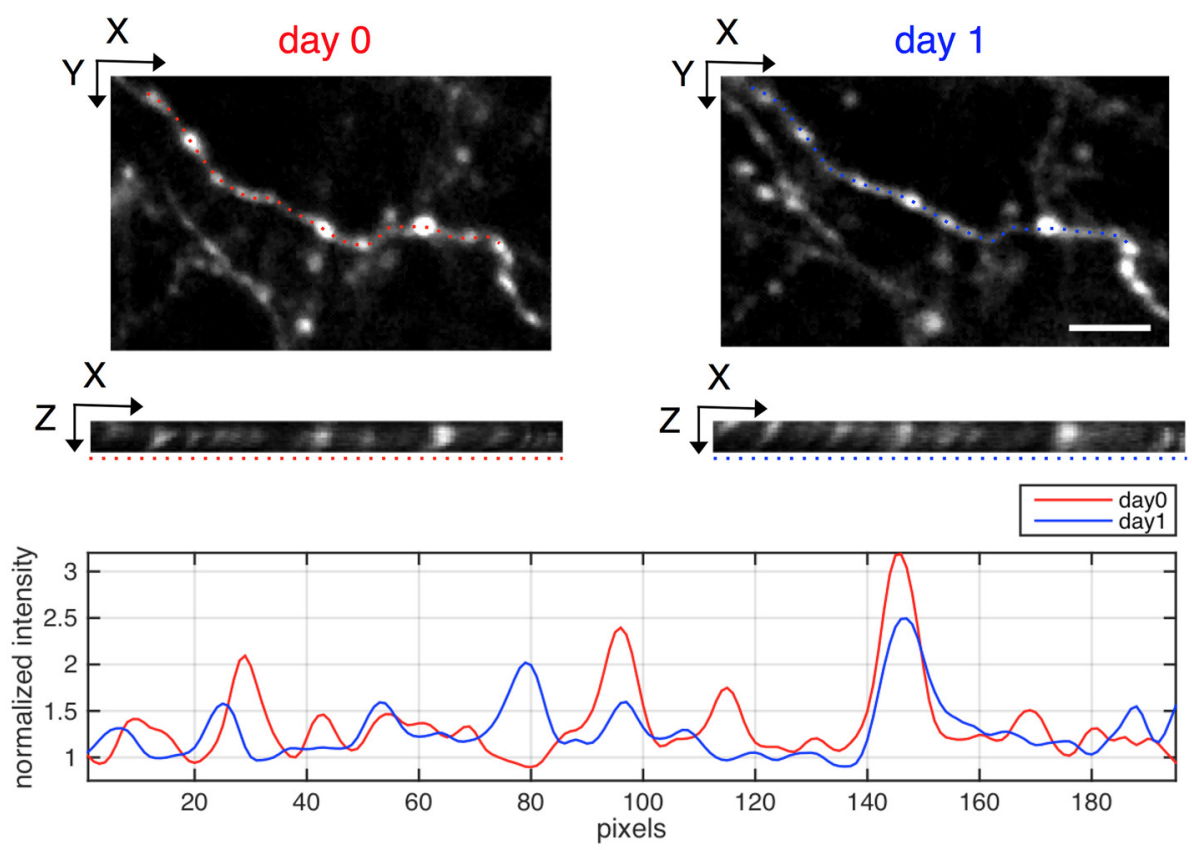

B

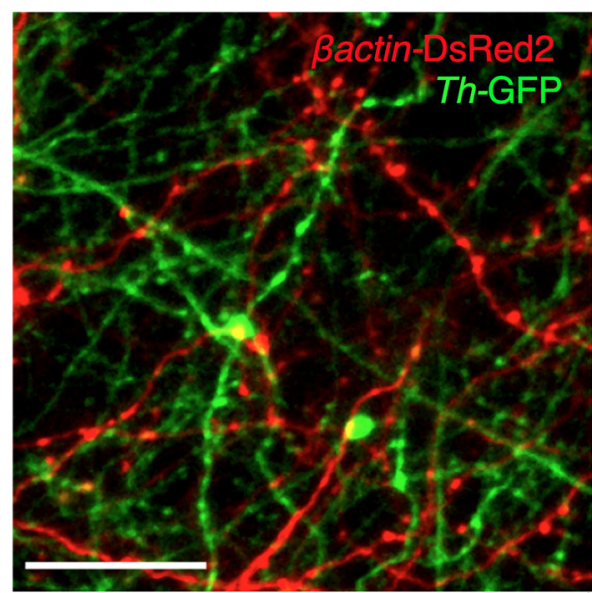

C
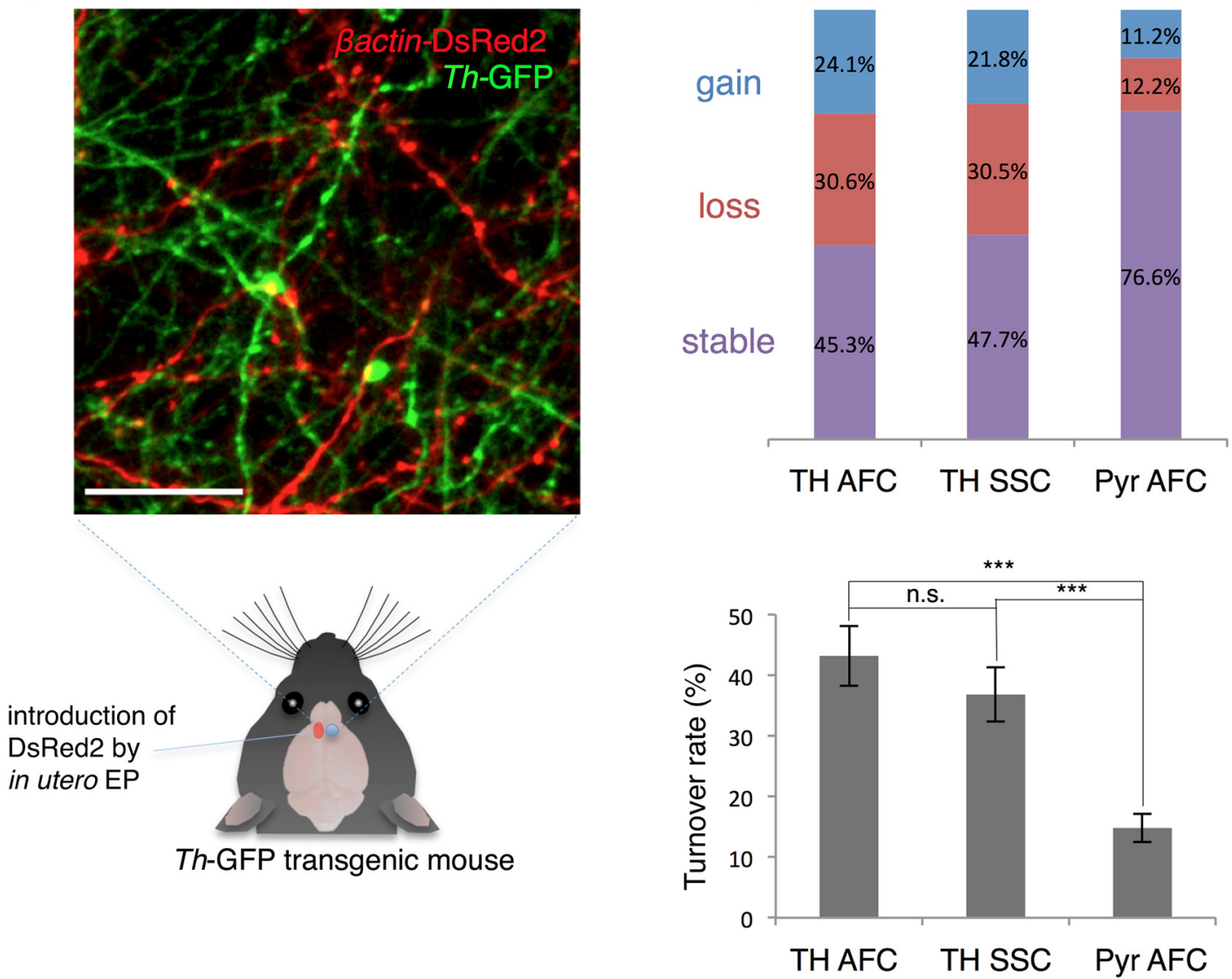

Figure 3. Bouton dynamics of catecholaminergic axons and pyramidal neurons over $24 \mathrm{~h}$. $\boldsymbol{A}$, Quantification of bouton dynamics over $24 \mathrm{~h}$. Well-isolated axonal arbors were selected for analysis (top: XY plane, middle: XZ plane along the axon; dotted line). Gained, lost, and stable boutons were scored based on the pixel intensity profile along the axon (bottom). Scale bar: $5 \mu \mathrm{m}$. B, Observation of Layer II/III pyramidal neuron axons (red) and catecholaminergic axons (green) within the same preparation in vivo. Scale bar: $25 \mu \mathrm{m}$. C, Top, Fraction of gained, lost, and stable boutons of dopaminergic axons in the AFC (TH AFC), catecholaminergic axons in the SSC (TH SSC), and pyramidal neuron axons in the AFC (Pyr AFC). TH AFC: $N=5, n=232$; TH SSC: $N=5, n=197$; Pyr AFC: $N=5, n=278$. Bottom, Comparison of TORs between axon types. $N$ : number of animals, $n$ : number of boutons. Data are presented as mean $\pm \mathrm{SEM}$; $* * * p<0.001$, n.s.: not significant. 
Table 1. Statistical table

\begin{tabular}{llll}
\hline & Data structure & Type of test & Power \\
a & Normal distribution & Two-tailed unpaired Student's $t$ test & $p=0.37$ \\
b & Normal distribution & Two-tailed unpaired Student's $t$ test & $p=1.9 \times 10^{-8}$ \\
c & Normal distribution & Two-tailed unpaired Student's $t$ test & $p=9.8 \times 10^{-7}$ \\
\hline
\end{tabular}

2011). These drugs also promote structural changes in the density of dendritic spines after prolonged administration in the rat neocortex (Robinson and Kolb, 2004; Koda et al., 2010). Would these drugs that alter the release of catecholamines affect the structure of catecholamine axons in vivo?

A single dose of MAP (2.5 or $10 \mathrm{mg} / \mathrm{kg}$ ) was administered subcutaneously during the imaging session. Stack images were obtained in intervals of 5-20 min. While a low dose administration ( $2.5 \mathrm{mg} / \mathrm{kg}$; data not shown) did not visibly change axonal structures, a high dose administration $(10 \mathrm{mg} / \mathrm{kg})$ induced a transient, but pronounced beads-on-a-string morphology in axons (Fig. 4A). This morphologic transition was characterized by an enlargement of the bouton diameter. We quantified the pixel intensity of the bouton as an index of its volume and analyzed the distribution of the intensities (normalized to the time of injection) in time epochs before injection of MAP, after injection, and after a recovery period. The catecholamine bouton intensities exhibited a skewed trend toward higher intensity after the injection (Fig. 4A). The fraction of boutons that increased in volume over 1.5 times after MAP injection reached $24.4 \%$, indicating that a significant portion of boutons increased in volume. However, this distribution returned to near baseline levels after the recovery period.

To investigate whether this bouton volume increase induced by MAP is specific to catecholamine neurons, we conducted the same experiment on $\mathrm{H}$-line mice, which express YFP in a subset of pyramidal neurons. In contrast to our previous results, these mice did not exhibit a clear change in the distribution of the bouton intensities after injection of MAP (Fig. 4B). Instead the pyramidal neurons seemed to show a different effect in which the volume change of the boutons were generally decreased after MAP injection, resulting in a narrower distribution around 1. We also controlled for the potential catecholaminergic neuron specific effects of the used anesthetics (ketamine and xylazine) by conducting the same experiment on an animal under a different anesthetic (isoflurene). We obtained similar results, and therefore did not find evidence for confounding effects of ketamine and xylazine (data not shown).

These results suggested that the bouton volume increase induced by MAP are likely mediated through molecular processes specific to catecholaminergic neurons. For example, MAP is known to act on DATs (dopamine reuptake transporters) expressed in dopamine neurons, to reverse its transport direction resulting in dopamine release (Sulzer et al., 2005). Indeed, after MAP injection, extracellular dopamine concentration (as measured by in vivo microdialysis during the same MAP injection condition) peaks within $1 \mathrm{~h}$, and decays thereafter (Fig. 5). The timing of the bouton volume increase precedes this ob- served rise of the dopamine concentration. These results support a model in which MAP triggers the transient bouton volume increase in the catecholamine neurons leading to the increase in the extracellular levels of dopamine. While the functional significance of this morphologic change is currently unknown, the changes may contribute to processes that underlie cognitive impairments, such as hallucination and psychosis experienced by high dose drug abusers (Wood et al., 2014).

\section{Discussion}

In this study, we observed the in vivo structural dynamics of catecholaminergic innervation to the neocortex, which are known to play a significant role in distinct cognitive functions as well as mental disorders.

The following were major findings:

1) Time lapse imaging over $24 \mathrm{~h}$ under normal condition revealed various morphological changes in catecholamine axons ranging from loss and gain of boutons and protrusions, to changes in the winding of the whole arbor (Figs. 1A, 2). The TORs of AFC and SSC boutons were both significantly higher than that of AFC Layer II/III pyramidal cell boutons. However, no significant difference was seen for catecholaminergic boutons between regions, suggesting an overall dynamic nature of catecholamine release sites in the neocortex (Fig. 3).

2) When a single high dose MAP was injected during the imaging session, we observed a transient beads-ona-string morphology of the axon (Fig. 4), which preceded the rise of extracellular DA concentration under the same condition (Fig. 5). This structural modification was found in catecholamine axons, but not in Layer II/III pyramidal cell axons (Fig. 4), suggesting a cell type-specific mechanism.

\section{High TOR of catecholaminergic axonal boutons}

Our analysis of bouton turnover yielded a higher TOR ( $\sim 50 \%$ dynamic fraction) for catecholaminergic axonal boutons compared to pyramidal cell axonal boutons ( $20 \%$ dynamic fraction; Fig. 3C). Such TOR of catecholaminergic axonal boutons seems constant even over a longer period (preliminary data; $N=3$ mice, 41 out of 80 boutons persisting over $4 \mathrm{~d}$ ). This suggests the existence of two distinct pools of boutons that have longer and shorter lifetimes, respectively.

The higher turnover of the observed catecholaminergic boutons could be due to the fact that most monoaminergic presynaptic release sites do not make synapses in the neocortex (Descarries et al., 1975), and uses the so-called "volume transmission" as their main strategy of transmission (Fuxe et al., 2010). Therefore, it can be hypothesized that, as a consequence of the presynaptic sites not being adhered to the postsynapse, the presynapse is not able to 
A Catecholaminergic neurons
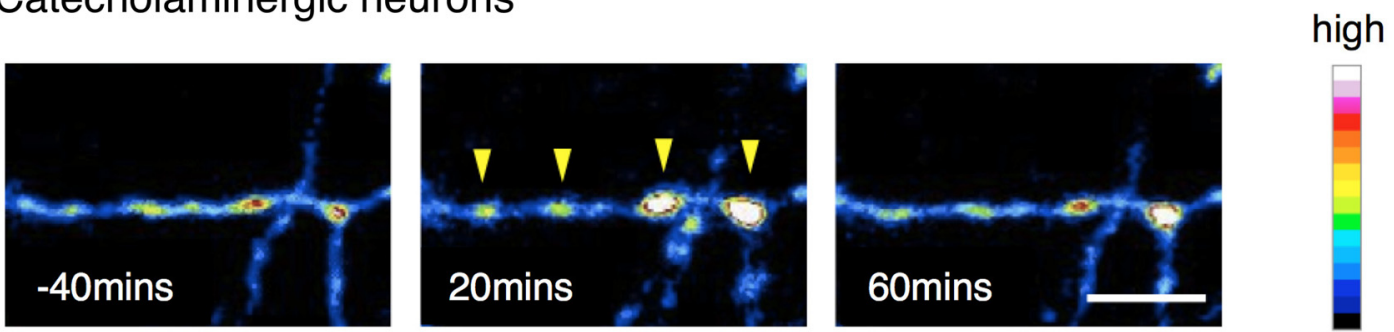

low
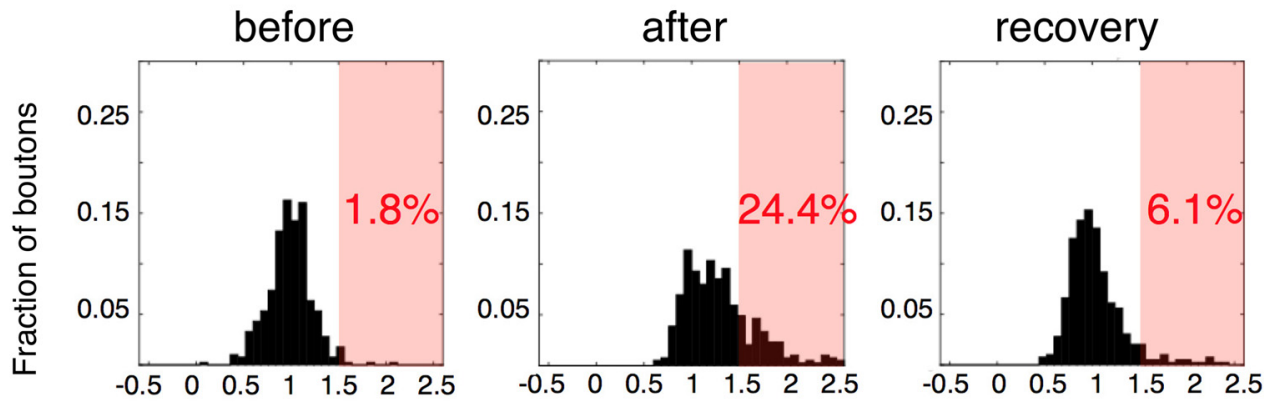

Normalized bouton intensity

\section{B Pyramidal neurons}
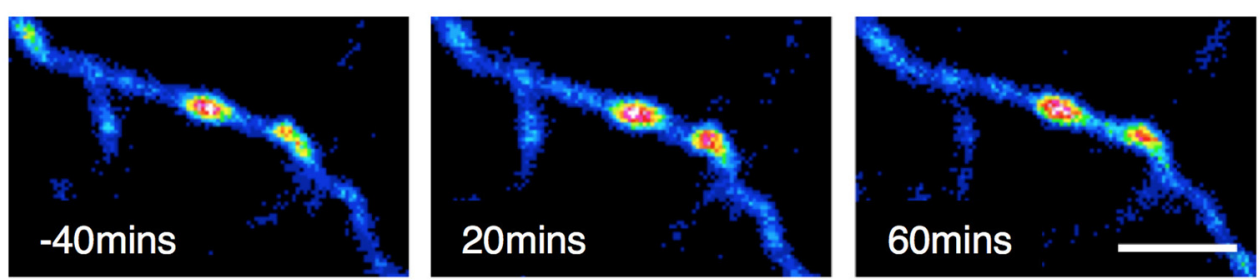

high
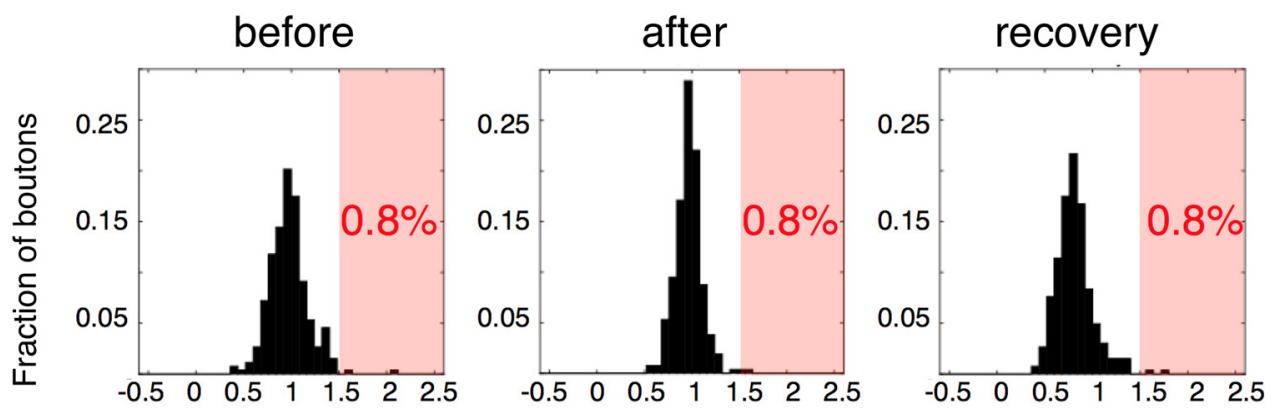

Normalized bouton intensity

Figure 4. Morphologic change of catecholaminergic boutons after MAP injection in the AFC. A single dose of MAP (10 mg/kg) induced a transient beads-on-a-string morphology in catecholaminergic neurons $(\boldsymbol{A})$, while in pyramidal neurons, there was no obvious structural change $(\boldsymbol{B})$; yellow arrowheads: enlarged boutons; scale bar: $10 \mu \mathrm{m}$. The histograms show bouton intensity normalized to MAP injection time point. After injection, the distribution of catecholaminergic bouton intensity shifted to above 1.5 times its original intensity (light red background), while pyramidal neuron boutons did not. Catecholamine neurons: $N=5, n=393$; pyramidal neurons: $N=5, n=263$ ( $N$ : number of animals, $n$ : number of boutons).

maintain itself at a specific location on the axonal shaft, and thus has a larger dynamic fraction. Another possibility could be that catecholamine boutons are induced or eliminated at certain locations in response to some molecular cue, to shift the site of local catecholaminergic transmission depending on the time of day or arousal level (Hobson and Pace-Schott, 2002). Whether this high dynamic fraction is due to such passive or active mechanism remains as a subject for future studies.

\section{Transient beads-on-a-string morphology induced by high-dose MAP administration}

Most studies that found structural changes in axonal boutons were conducted in vitro and report neurotoxicity 


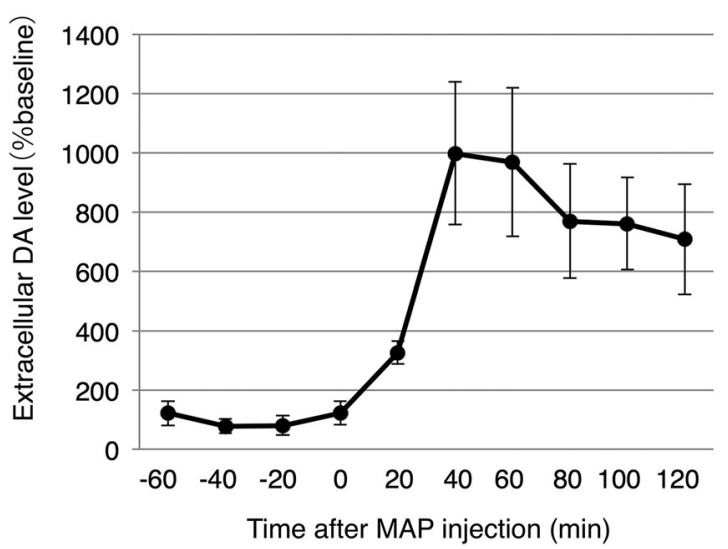

Figure 5. Extracellular dopamine concentration measured by microdialysis in the AFC. Mice were kept under anesthesia in an identical condition to the in vivo imaging experiments. A single dose of MAP (10 mg/kg) was injected at time 0 and was monitored in 20 min intervals. $N=4$ mice.

of the MAP leading to blebbing of axons and subsequent cell death (Cubells et al., 1994; Larsen et al., 2002). The phenomenon we observed is unlikely to be part of such cell death processes, because the axons returned to its original morphology after a recovery period (Fig. 4).

Morphologic changes of axonal compartments are known to relate to functional changes such as the regulation of transmitter release. Here we observed a significant bouton volume change with a MAP injection, which was specific to catecholaminergic axons. This indicates that the molecular pathways in which MAP affect catecholaminergic neurons result in a bouton volume change as well as the increase in transmitter release (Fig. 5). We therefore speculate that this novel bouton volume change reported here, is part of the mechanism for the increased transmitter release.

We also observed variability in the extent of bouton volume change (Fig. 4), which may reflect some kind of variability in the susceptibility to MAP among boutons. One study which looked at the ultrastructure of striatal dopaminergic boutons in rats treated with MAP daily for two weeks found that the decrease in bouton number was specific to the population of boutons without mitochondria, and the boutons with mitochondria stayed intact (Ihara et al., 1986). Ultrastructural analysis of affected and non-affected boutons may provide mechanistic insights into this structural change in the future.

\section{Applicability of Th-GFP transgenic mice for longitudinal in vivo imaging}

By exploiting this method for longitudinal in vivo imaging, the utility of Th-GFP mice can be significantly expanded for a variety of experiments in the future. Catecholamine axons are known to continuously develop for an extended period of time after birth (Pascucci et al., 2007; Segovia et al., 2008). Therefore, imaging of axonal process during early development would provide insights into how catecholaminergic axons integrate into preexisting, or developing cortical circuits. Since learning related structural plasticity is known to occur at dendritic spines (Matsuzaki et al., 2004; Xu et al., 2009), it would be of interest to observe whether the cat- echolaminergic boutons would also structurally change in vivo especially under reinforcement learning paradigms. $\mathrm{TH}$ positive projections from the LC to the hippocampus were recently found to mediate novelty-associated memory enhancement (Takeuchi et al., 2016). Therefore, it would also be intriguing to observe the dynamics of the TH projections in vivo during the process of such plasticity in the hippocampus using this method. On the other hand, deficits in catecholaminergic innervation are implicated in some mental disorders including schizophrenia (Akil et al., 1999; Sekiguchi et al., 2011). Th-GFP mice could be crossed to mouse models of mental disorders to investigate alterations in the structural dynamics of those strains and to correlate differences in the axonal dynamics with behavioral and physiologic changes. Taken together, this new capability to follow dynamic changes of catecholaminergic axons longitudinally would be useful for asking important questions related to the development of cortical circuits, learning related plasticity, and for understanding mechanisms underlying alterations in the catecholamine system that result in mental disorders.

\section{References}

Akil M, Pierri JN, Whitehead RE, Edgar CL, Mohila C, Sampson AR, Lewis DA (1999) Lamina-specific alterations in the dopamine innervation of the prefrontal cortex in schizophrenic subjects. Am J Psychiatry 156:1580-1589. CrossRef

Arnsten AF (1998) Catecholamine modulation of prefrontal cortical cognitive function. Trends in Cogn Sci 2:436-447. CrossRef

Berger B, Thierry AM, Tassin JP, Moyne MA (1976) Dopaminergic innervation of the rat prefrontal cortex: a fluorescence histochemical study. Brain Res 106:133-145. CrossRef

Bubser M, Schmidt WJ (1990) 6-Hydroxydopamine lesion of the rat prefrontal cortex increases locomotor activity, impairs acquisition of delayed alternation tasks, but does not affect uninterrupted tasks in the radial maze. Behav Brain Res 37:157-168. CrossRef

Cubells JF, Rayport S, Rajendran G, Sulzer D (1994) Methamphetamine neurotoxicity involves vacuolation of endocytic organelles and dopamine-dependent intracellular oxidative stress. J Neurosci 14:2260-2271.

Darvesh AS, Carroll RT, Geldenhuys WJ, Gudelsky GA, Klein J, Meshul CK, Van der Schyf CJ (2011) In vivo brain microdialysis: advances in neuropsychopharmacology and drug discovery. Expert Opin Drug Discov 6:109-127. CrossRef

De Paola V, Holtmaat A, Knott G, Song S, Wilbrecht L, Caroni P, Svoboda K (2006) Cell type-specific structural plasticity of axonal branches and boutons in the adult neocortex. Neuron 49:861-875. CrossRef

Descarries L, Beaudet A, Watkins KC (1975) Serotonin nerve terminals in adult rat neocortex. Brain Res 100:563-588. Medline

Feng G, Mellor RH, Bernstein M, Keller-Peck C, Nguyen QT, Wallace M, Nerbonne JM, Lichtman JW, Sanes JR (2000) Imaging neuronal subsets in transgenic mice expressing multiple spectral variants of GFP. Neuron 28:41-51.

Fuxe K, Dahlström AB, Jonsson G, Marcellino D, Guescini M, Dam $M$, Manger $P$, Agnati L (2010) The discovery of central monoamine neurons gave volume transmission to the wired brain. Prog Neurobiol 90:82-100. CrossRef

Gamo NJ, Arnsten AFT (2011) Molecular modulation of prefrontal cortex: rational development of treatments for psychiatric disorders. Behav Neurosci 125:282-296. CrossRef

Hobson JA, Pace-Schott EF (2002) The cognitive neuroscience of sleep: neuronal systems, consciousness and learning. Nat Rev Neurosci 3:679-693. CrossRef

Holtmaat A, Bonhoeffer T, Chow DK, Chuckowree J, De Paola V, Hofer SB, Hübener M, Keck T, Knott G, Lee WC, Mostany R, Mrsic-Flogel TD, Nedivi E, Portera-Cailliau C, Svoboda K, Tra- 
chtenberg JT, Wilbrecht L (2009) Long-term, high-resolution imaging in the mouse neocortex through a chronic cranial window. Nat Protoc 4:1128-1144. CrossRef Medline

Holtmaat AJ, Trachtenberg JT, Wilbrecht L, Shepherd GM, Zhang X, Knott GW, Svoboda K (2005) Transient and persistent dendritic spines in the neocortex in vivo. Neuron 45:279-291. CrossRef

Huang ZJ, Taniguchi H, He M, Kuhlman S (2014) Cre-dependent adeno-associated virus preparation and delivery for labeling neurons in the mouse brain. Cold Spring Harb Protoc 2014:190-194. CrossRef

Ihara Y, Sato M, Otsuki S, Kaiya H, Namba M (1986) Morphological changes in rat striatal boutons after chronic methamphetamine and haloperidol treatment. Neurosci Res 3:403-410. CrossRef

Isshiki M, Tanaka S, Kuriu T, Tabuchi K, Takumi T, Okabe S (2014) Enhanced synapse remodelling as a common phenotype in mouse models of autism. Nature Communications, 5:4742. CrossRef

Koda K, Ago Y, Cong Y, Kita Y, Takuma K, Matsuda T (2010) Effects of acute and chronic administration of atomoxetine and methylphenidate on extracellular levels of noradrenaline, dopamine and serotonin in the prefrontal cortex and striatum of mice. J Neurochem 114:259-270.

Lammel S, Steinberg EE, Földy C, Wall NR, Beier K, Luo L, Malenka RC (2015) Diversity of transgenic mouse models for selective targeting of midbrain dopamine neurons. Neuron 85:429-438. CrossRef

Larsen KE, Fon EA, Hastings TG, Edwards RH, Sulzer D (2002) Methamphetamine-induced degeneration of dopaminergic neurons involves autophagy and upregulation of dopamine synthesis. J Neurosci 22:8951-8960.

Lee WC, Huang H, Feng G, Sanes JR, Brown EN, So PT, Nedivi E (2005) Dynamic remodeling of dendritic arbors in GABAergic interneurons of adult visual cortex. PLoS Biol 4:e29. CrossRef

Li BM, Mei ZT (1994) Delayed-response deficit induced by local injection of the alpha 2-adrenergic antagonist yohimbine into the dorsolateral prefrontal cortex in young adult monkeys. Behav Neural Biol 62:134-139. CrossRef

Lindvall O, Björklund A, Divac I (1978) Organization of catecholamine neurons projecting to the frontal cortex in the rat. Brain Res 142:1-24. Medline

Mastwal S, Ye Y, Ren M, Jimenez DV, Martinowich K, Gerfen CR, Wang KH (2014) Phasic dopamine neuron activity elicits unique mesofrontal plasticity in adolescence. J Neurosci 34:9484-9496. CrossRef

Matsushita N, Okada H, Yasoshima Y, Takahashi K, Kiuchi K, Kobayashi K (2002) Dynamics of tyrosine hydroxylase promoter activity during midbrain dopaminergic neuron development. J Neurochem 82:295-304. CrossRef

Matsuzaki M, Honkura N, Ellis-Davies GC, Kasai H (2004) Structural basis of long-term potentiation in single dendritic spines. Nature 429:761-766.

Nagayama S, Homma R, Imamura F (2014) Neuronal organization of olfactory bulb circuits. Fron Neural Circuits 8:98. CrossRef

Pascucci T, Ventura R, Latagliata EC, Cabib S, Puglisi-Allegra S (2007) The medial prefrontal cortex determines the accumbens dopamine response to stress through the opposing influences of norepinephrine and dopamine. Cereb Cortex 17:2796-2804. CrossRef

Robbins TW, Arnsten AFT (2009) The neuropsychopharmacology of fronto-executive function: monoaminergic modulation. Annu Rev Neurosci 32:267-287. CrossRef Medline
Robinson TE, Kolb B (2004) Structural plasticity associated with exposure to drugs of abuse. Neuropharmacology 47[Suppl 1]:3346. CrossRef Medline

Sawaguchi T, Goldman-Rakic P (1991) D1 dopamine receptors in prefrontal cortex: involvement in working memory. Science 251: 947-950.

Schultz W, Dayan P, Montague PR (1997) A neural substrate of prediction and reward. Science 275:1593-1599. Medline

Seamans JK, Yang CR (2004) The principal features and mechanisms of dopamine modulation in the prefrontal cortex. Prog Neurobiol 74:1-58. CrossRef Medline

Segovia G, Del Arco A, de Blas M, Garrido P, Mora F (2008) Effects of an enriched environment on the release of dopamine in the prefrontal cortex produced by stress and on working memory during aging in the awake rat. Behav Brain Res 187:304-311. CrossRef

Sekiguchi H, Iritani S, Habuchi C, Torii Y, Kuroda K, Kaibuchi K, Ozaki N (2011) Impairment of the tyrosine hydroxylase neuronal network in the orbitofrontal cortex of a genetically modified mouse model of schizophrenia. Brain Res 1392:47-53. CrossRef

Smiley JF, Williams SM, Szigeti K, Goldman-Rakic PS (1992) Light and electron microscopic characterization of dopamineimmunoreactive axons in human cerebral cortex. J Comp Neur 321:325-335. CrossRef

Stuber GD, Stamatakis AM, Kantak PA (2015) Considerations when using cre-driver rodent lines for studying ventral tegmental area circuitry. Neuron 85:439-445. CrossRef

Sulzer D, Sonders MS, Poulsen NW, Galli A (2005) Mechanisms of neurotransmitter release by amphetamines: a review. Prog Neurobiol 75:406-433. CrossRef

Takeuchi T, Duszkiewicz AJ, Sonneborn A, Spooner PA, Yamasaki M, Watanabe M, Smith CC, Fernández G, Deisseroth K, Greene RW, Morris RG (2016) Locus coeruleus and dopaminergic consolidation of everyday memory. Nature 537:357-362.

Van De Werd HJ, Rajkowska G, Evers P, Uylings HB (2010) Cytoarchitectonic and chemoarchitectonic characterization of the prefrontal cortical areas in the mouse. Brain Struct Funct 214:339353 CrossRef

Vijayraghavan S, Wang M, Birnbaum SG, Williams GV, Arnsten AF (2007) Inverted-U dopamine D1 receptor actions on prefrontal neurons engaged in working memory. Nat Neurosci 10:376-384. CrossRef

Wood S, Sage JR, Shuman T, Anagnostaras SG (2014) Psychostimulants and cognition: a continuum of behavioral and cognitive activation. Pharmacol Rev 66:193-221. CrossRef Medline

Xu T, Yu X, Perlik AJ, Tobin WF, Zweig JA, Tennant K, Jones T, Zuo $Y$ (2009) Rapid formation and selective stabilization of synapses for enduring motor memories. Nature 462:915-919. CrossRef Medline

Yagishita S, Hayashi-Takagi A, Ellis-Davies GC, Urakubo H, Ishii S, Kasai $\mathrm{H}$ (2014) A critical time window for dopamine actions on the structural plasticity of dendritic spines. Science 345:1616-1620. CrossRef Medline

Zahrt J, Taylor JR, Mathew RG, Arnsten AF (1997) Supranormal stimulation of D1 dopamine receptors in the rodent prefrontal cortex impairs spatial working memory performance. J Neurosci $17: 8528-8535$

Zhang X, van den Pol AN (2015) Dopamine/tyrosine hydroxylase neurons of the hypothalamic arcuate nucleus release GABA, communicate with dopaminergic and other arcuate neurons, and respond to dynorphin, met-enkephalin, and oxytocin. J Neurosci 35:14966-14982. CrossRef 